UM URBANO PRA LÁ DE RURAL: AS PARTICULARIDADES POLÍTICAS, HISTÓRICAS E CULTURAIS QUE TRANSFORMARAM CAMPO GRANDE DE ARRAIAL A CAPITAL

UM URBANO PRA LA DE RURAL: THE POLITICAL, HISTORICAL AND CULTURAL PARTICULARITIES THAT MADE CAMPO GRANDE OF ARRAIAL TO A CAPITAL

Daniel Attianesi

Guilherme RodriguesPassamani

Como citar este artigo:

ATTIANESI, Daniel; PASSAMANI, Guilherme R. Um urbano pra lá de rural: as particularidades políticas, históricas e culturais que transformaram Campo Grande de arraial a capital.In: Cadernos do Lepaarq, v. XV, n.30., p. 56-68, Jul-Dez. 2018. 


\title{
Um urbano pra lá de rural: as particularidades políticas, históricas e culturais que transformaram Campo Grande de arraial a capital
}

\author{
Daniel Attianesi $\mathrm{i}^{\mathrm{a}}$ \\ Guilherme Rodrigues Passamani ${ }^{\mathrm{b}}$
}

\begin{abstract}
Resumo: Ao pensar sobre a cidade de Campo Grande, estamos pensando em nexos constitutivos da própria realidade de diversas cidades brasileiras e do próprio Estado de Mato Grosso do Sul, cuja capital política e administrativa possui como sede o município de Campo Grande. Este artigo realizará uma análise da história de Campo Grande de forma a pensar a questão da relação entre rural e urbano. Dessa forma, buscamos três momentos específicos dessa história: o primeiro sendo a formação de uma identidade cultural sul-mato-grossense entre os anos de 1932 a 1934, o segundo será pensar o momento de urbanização da cidade nos anos de 1960-1970 e, no último, iremos pensar a relação que a cidade possui atualmente com seus habitantes.
\end{abstract}

\section{Palavras Chave:}

Campo Grande; Cidade; Mato Grosso do Sul; Antropologia Urbana.

\begin{abstract}
When thinking about the City of Campo Grande, we are thinking in constitutive links with the reality of many Brazilian cities and with the very State of Mato Grosso do Sul, whose political and administrative capital is based in the City of Campo Grande. This article's will analyze the history of Campo Grande in order to think about the relationship between rural and urban. In this way, we look for three specific moments of this history: the first one being the formation of a cultural identity of the people of Mato Grosso do Sul from 1932 to 1934; The second is to think about the moment of the city's urbanization in the years 1960-1970 and the latter we'll think about the relationship that the city currently has with its inhabitants.
\end{abstract}

\section{Keywords:}

Campo Grande; City; Mato Grosso do Sul; Urban Anthropology. 
"Campo Grande é a primeira cidade mato-grossense que vamos ver com algum vagar.

Começaram as surpresas! Naquela distância de São Paulo, e depois de atravessada uma zona extensíssima de campos e florestas sem quase nenhum vestígio humano, a gente imagina o que será o tal Campo Grande: casebres de palha, igrejinha duma torre só, Rua João Pessoa, tabaréus de chapelão e faca à cinta, caras lampionescas, rastros de onça pintada pelas ruas barrentas. Todas essas expectativas falham.

Campo Grande surpreende e força a ejeção de adjetivos sinceríssimos.

Porque aquilo não é cidade de fim de civilização, de beira-sertão, como o viajante logicamente é levado a supor. É cidade de começo de civilização, é a coisa mais reconfortadora que em tais alturas alguém possa esperar.

Mas o melhor de Campo Grande não é o que Campo Grande já é e sim o que promete ser. Reúnem-se nela todas as condições favoráveis para ser uma das grandes futuras cidades do Brasil. Subirá a 50 mil a 100 mil, a 200 mil habitantes e parece que o urbanista que lhe traçou as ruas e praças teve perfeita consciência disso. Tudo em Campo Grande é grande, espaçoso, arejado. ”(LOBATO, 1940. p. 245)

\section{O INÍCIO DE CAMPÃO}

A ideia para esse artigo surgiu de uma das aulas no curso de Antropologia Urbana. Durante as aulas ministradas, o professor sempre demonstrou curiosidade sobre pensar a cidade que vivemos a partir das leituras dos diversos autores presentes na disciplina. Buscamos identificar como pensar a identidade de Campo Grande como uma capital em contraste com as outras capitais próximas ao estado. Campo Grande é a capital de um estado que possui 95,2\% das exportações apenas em produtos agrícolas ${ }^{1}$ e que cujo próprio nome remete à ideia de "Campo" no sentido agropecuário do termo. Isso nos faz pensar em outras nuances de perspectivas de uma cidade urbanizada que não nos mesmos moldes tradicionais costumeiros dos textos clássicos de antropologia urbana.

Esse artigo busca pensar a questão da urbanização como fundamento para uma primeira fase no estudo do urbano na antropologia, sendo ela considerada um estudo da cidade ao invés de um estudo na cidade (OLIVEN, 1980, p. 29). Para isso, utilizamos os clássicos da área, como os precursores Georg Simmel e Max Weber, além de autores da Escola de Chicago como Robert Ezra Park e Louis Wirth (BECKER, 1996).

Outro fato que ao mesmo tempo que desperta o interesse se mostra também uma dificuldade de se trabalhar com a cidade, é o de sermos recém imigrados ${ }^{2}$ em Campo Grande. Buscamos observar a cidade de uma forma diferente que a vista por seus habitantes não imigrados. Há dificuldades pois não estamos tão familiarizados com a história da cidade e sua constituição como capital do estado.

O escopo deste artigo inicia a partir dos anos 30, data essa escolhida devido a ser marcada por historiadores, como Marisa Bittar (BITTAR, 1997,137), que nos mostram que nessa década podemos começar a ver um movimento dentro nas es-feras políticas como forma de luta pelos interesses do sul do Mato Grosso e a constituição da cidade de Campo Grande. Tendo isso em vista, essa presente introdução busca fazer um resumo dos antecedentes da formação da cidade de Campo Grande. Nesse sentido, partimos de um breve histórico ${ }^{3}$, tendo início após o final da Guerra com o Paraguai, intensifica-se um processo de imigração (que se dá em maioria pela migração de cuiabanos, goianos, mineiros, paulistas e gaúchos) para a região sul do Mato Grosso. No ano de 1872, o futuro fundador de Campo Grande, José Antônio Pereira, acompanhado por seus filhos e mais alguns homens, sai de Monte Alegre, no estado de Minas Gerais, de onde diversos outros já haviam saído, rumo às terras do sul do Mato Grosso.

\footnotetext{
1 MSPONTOCOM. Agronegócio domina exportações em Mato Grosso do Sul em 2016. Disponível em: < http://mspontocom.com.br/site/ agronegocio-domina-exportacoes-em-mato-grosso-do-sul-em-2016/>. Acesso em: 05 ago. 2017.

2 A questão de imigração se mostrou interessante durante a pesquisa como uma questão de grande importância para a formação da cidade.

3 Esse breve histórico foi retirado da página da prefeitura do estado. Fonte: Campo Grande (MS). 2013. Arquivo Histórico de Campo Gran-

de. Disponível em: http://www.capital.ms.gov.br. Acesso em: mar/2017.
}

Attianesi, Daniel; PASSAMANI, Guilherme R. Um urbano pra lá de rural... In: Cadernos do Lepaarq, v. XV, n.30., p. 56-68, Jul-Dez. 2018. 
Atravessaram a região do rio Paranaíba, adentraram o sul do Mato Grosso, passando pelo rio Sucuriú, transpuseram os cerradões do rio Pardo e acamparam nas terras da Serra de Maracaju. O que chamou a atenção de José Antônio Pereira nessas terras foi o frescor do milharal e dos outros cereais cultivados por posseiros. Inspecionou o local, constatando a fertilidade do solo, a amenidade do clima e a existência de boas pastagens. Logo, esses fatores convenceram José Antônio Pereira a não prosseguir viagem e iniciar uma plantação ali, a exemplo de diversos outros posseiros que já existiam na região sul do Mato Grosso.

No início do ano seguinte, José Antônio Pereira regressa a Minas Gerais, de onde retornaria três anos depois, com toda a sua família e alguns agregados, sendo a comitiva composta de sessenta e duas pessoas. Em agosto de 1875 chega à região do que viria a ser chamado de Campo Grande, conduzindo sua expedição composta de onze carros mineiros, os quais, além das provisões necessárias para os primeiros tempos, traziam também semente e mudas diversas, inclusive cana-de-açúcar e café. Assim, surgiria primeiro uma fazenda na região que apenas em 1889 seria elevada a distrito ${ }^{4}$, à vila no ano de $1899^{5}$ e, somente em $1918^{6}$, viria a ser considerada a cidade de Campo Grande.

A localização da cidade de Campo Grande se mostrará interessante aos objetivos econômicos e estratégicos da Companhia de Estrada de Ferro Noroeste do Brasil, que com isso sediou uma diretoria regional que atenderia todo o sul do estado do Mato Grosso. Também próximo a esse período, em 1921, através do Ministério da Guerra, houve a transferência do comando da Circunscrição Militar de Corumbá para Campo Grande, tornando a cidade uma “capital” militar da região.

Além disso, na década de 1930, observou-se o crescimento da importância socioeconômica e política. Há o início das discussões sobre a divisão do estado do Mato Grosso na cidade de Campo Grande. O processo de divisão do estado e constituição de Campo Grande como a capital do novo estado ocupará as seções seguintes. Daremos especial atenção aos aspectos que intersectam rural e urbano na edificação da capital

\section{DIVISIONISMO E IDENTIDADE: A LIBERTAÇÃO DO SUL}

Utilizamos a classificação do movimento divisionista realizado pela elite campo-grandense presente no artigo Mato Grosso do Sul: Uma trajetória divisionista, publicado pela professora da Universidade Católica Dom Bosco (UCDB), Alisolete Antônia dos Santos Weingartner ${ }^{7}$. Nessa parte do artigo, o período definido pela autora será o do segundo momento, de 1930-1945, período em que o movimento divisionista começa a se organizar. Há pressões políticas junto ao governo federal, assim como confronto armado.

Como a autora acima, também entendemos que contribua para a importância da década de 1930 o movimento divisionista e a formação de uma identidade do Mato Grosso do Sul, fatos presentes também na dissertação de mestrado de Carlos Amarilha, intitulada Os Intelectuais e o Poder: História, Divisionismos e Identidade em Mato Grosso do Sul, de 2006. Amarilha também reconheceu a importância da década de 1930, demonstrando que "as imagens inculcadas pelos intelectuais nortistas e as ações políticas do governo estadual não eram bem recebidas, por parte de uma elite em ascensão no sul do Mato Grosso, principalmente por moradores da cidade de Campo Grande, sobretudo a partir da década de 1930" (AMARILHA, 2006, p. 51).

\footnotetext{
4 Distrito criado com a denominação de Campo Grande pela Lei n. ${ }^{\circ}$ 792, de 23-11-1889.

5 Elevado à categoria de vila com a denominação de Campo Grande, pela Resolução Estadual n. ${ }^{\circ} 225$, de 26-08-1899.

6 Elevado à condição de cidade com a denominação de Campo Grande, pela Lei Estadual n. ${ }^{\circ}$ 772, de 16-07-1918.

7 SANTOS, Alisolete Antônia Weingartner dos. Movimento Divisionista em Mato Grosso do Sul (1889-1930). 1. Ed. Porto Alegre: Edições Est, 1995.
}

Attianesi, Daniel; PASSAMANI, Guilherme R. Um urbano pra lá de rural... In: Cadernos do Lepaarq, v. XV, n.30., p. 56-68, Jul-Dez. 2018. 
Temos, nesse período, o momento em que a cidade de Campo Grande, por meio de determinados políticos, fazendeiros e intelectuais, busca criar uma rejeição ao que denominariam "dominação nortista” sobre o sul do Mato Grosso. Como demonstrado na introdução, a cidade ganhará importância com a construção da Estrada de Ferro Noroeste do Brasil, possibilitando que se criem discursos a seu favor, de maneira a configurar o município como moderno. Corroborando essa ideia, Paulo Roberto Cimó Queiroz argumenta que:

Pelo que se pode perceber, foi ao longo da década de 1920 que começaram a manifestar-se, mais claramente, os efeitos considerados positivos da estrada de ferro Noroeste do Brasil, efeitos esses que se concentram largamente na cidade de Campo Grande, sob a forma de rápido crescimento econômico e populacional. (QUEIROZ, 2005, p. 7)

Dessa forma, com o crescimento da importância econômica e política da região, parte da elite sul-mato-grossense, principalmente universitários campo-grandenses que estudavam na capital federal, fundaram a Liga Sul-Mato-Grossense, entidade essa que possuía como objetivo a divisão de Mato Grosso. Sobre essa questão, Queiroz (2005, p. 8) nos diz que as "[...] elites sulistas, ou pelo menos parte delas [...] parecem haver decidido radicalizar suas posições passando a defender por escrito e abertamente, pela primeira vez, a separação entre o Sul e o 'Norte' do Estado". Nos manifestos lançados pela Liga Sul-Mato-Grossense era reivindicada a criação de um novo estado na porção sul do Mato Grosso, indicando a cidade de Campo Grande para ser a capital.

Surge então, em fins de 1932, a Liga Sul-mato-grossense, fundada no Rio de Janeiro que lança três documentos principais: um Manifesto aos habitantes do sul de Mato Grosso, datado de outubro de 1933; um Manifesto da mocidade do sul de Mato Grosso ao Chefe do Governo Provisório e à Assembleia Constituinte, datado de janeiro de 1934; e uma Representação dos sulistas ao Congresso Nacional Constituinte, aparentemente de março de 1934, acompanhada de um abaixo-assinado com milhares de assinaturas (documentos esses reproduzidos in MARTINS, 1944, p. 90 e ss.). Um outro documento, de teor semelhante, rebatendo críticas do então general Rondon às pretensões dos sulistas e assinado por personalidades de destaque nessa região, foi publicado em Campo Grande em março de 1934 (A divisão de Mato Grosso: resposta ao General Rondon). (QUEIROZ, 2005, p. 8-9)

Esses manifestos serviram de base para o movimento divisionista das elites sulistas ${ }^{8}$ começar a pensar sobre a formação de uma identidade sul-mato-grossense. O primeiro (de outubro 1933) dos manifestos busca apresentar para a população sul-mato-grossense a Liga como uma entidade divulgadora do engrandecimento de sua terra natal ${ }^{9}$. Com isso, se busca o que Robert Park nos diz sobre a "[...] opinião pública torna-se importante como uma fonte de controle social em sociedades ba-seadas em relações secundárias, de que as cidades grandes são típicas” (PARK,1967, p. 59).

Já no segundo e terceiro (de janeiro e março de 1934) manifesto, temos o interesse da Liga em influenciar o chefe do governo provisório e os políticos da Assembleia Nacional Constituinte ${ }^{10}$. Mas ao fim dos trabalhos da constituinte de 1934, as demandas da Liga são negadas não sendo dividido nem criado um novo estado no Mato Grosso.

Ainda assim, ressaltamos aqui no artigo a importância que a Liga possuía para o ideal de urbanidade e modernidade da cidade de Campo Grande, por meio de sua elite, assim como nos diz Carlos Amarilha em dois momentos ao falar sobre a cidade: no primeiro momento, que ela é "voltada para o progresso e para o desenvolvimento; além disso, incluem nesses

8 Ao pensarmos nessas elites que fundaram a Liga Sul-Mato-Grossense, devemos ter em mente que se compõe de fazendeiros, comerciantes, políticos, profissionais liberais e militares, (universitários que estudavam no Rio de Janeiro e São Paulo), sobretudo da cidade de Campo Grande, que, de uma forma ou de outra lutavam pelo poder de mando (AMARILHA, 2005, p. 67).

9 De certa forma, acabam construindo, também, uma identidade própria, de pertencimento, sulista ou sul-mato-grossense em rejeição ao outro (cuiabano) (AMARILHA,2005, p. 65).

10 Nesse período pós-revolução do 1932, o governo provisório de Getúlio Vargas passava por um momento de enfraquecimento e havia convocado uma assembleia nacional constituinte para elaboração de uma nova constituição federal. 
documentos que a cidade estaria mais bem preparada para se inserir na modernidade do século XX do que a capital Cuiabá" (AMARILHA, 2005, p. 84), e também no segundo momento em que afirma que

\begin{abstract}
[...] os divisionista elegem a cidade de Campo Grande como lugar por excelência da modernidade, numa projeção otimista e frequentemente acrítica. Campo Grande é concebida como fulcro irradiador de um novo modo de civilização, em uma série de metáforas que acrescenta novos tropos às substâncias interativas da imaginação letrada regional. Assim, Campo Grande passa a ser a cidade do progresso, protótipo da civilização e do desenvolvimento. Por isso, Campo Grande, segundo os divisionistas, apresentava todos os requisitos para ser uma capital" (AMARILHA, 2005, p. 85).
\end{abstract}

Já nesse momento podemos observar como a questão da modernidade e da cidade se mostram fundamentais na medida em que já se encontram associadas uma à outra. Observamos que a Liga Sul-Mato-Grossense se constitui com a ideia de Campo Grande como a nova capital do futuro Mato Grosso do Sul, de forma a ser vista como o "[...] centro iniciador e controlador da vida econômica, política e cultura que atraiu as localidades mais remotas do mundo para dentro de sua órbita e interligou as diversas áreas, os diversos povos e as diversas atividades num universo" (WIRTH, 1967, p. 89).

\title{
MODERNIZAÇÃO DO CAMPO (GRANDE)
}

Apesar de já percebermos o início de uma concepção da cidade de Campo Grande enquanto um polo moderno e progressista no Sul do Mato Grosso nos anos 1930, acreditamos nesse artigo que o momento em que podemos pensar numa distinção entre o rural e o urbano, na cidade de Campo Grande, pode ser traçado a partir do processo de modernização e crescimento acentuado nas décadas de 1960 e 1970. Para tanto aqui, compreendemos modernização como:

[...] processos de transformações profundas e frequentemente rápidas tiveram repercussões imediatas no sistema internacional e foram exportadas pelos europeus para toda a parte, mesmo que só vingassem lenta e parcialmente. É essa a razão por que o processo global foi designado com o nome de europeização, ocidentalização ou, enfim, com o termo mais abrangente e menos etnocêntrico de Modernização. (PASQUINO, 2000, p. 768)

Que por sua vez trará um

[...] tipo metropolitano de individualidade que consiste na intensificação dos estímulos nervosos [...] O ritmo e a multiplicidade da vida econômica, ocupacional e social, a cidade faz um contraste profundo com a vida de cidade pequena e a vida rural no que se refere aos fundamentos sensoriais da vida psíquica. (SIMMEL, 1973, p. 12)

Esse processo da modernização da cidade de Campo Grande, ainda na primeira metade do século XX, foi bastante documentado, assim como o crescimento da cidade, com dados de censos sobre a população urbana e rural do município, a partir da construção dos trilhos da Estrada de Ferro Noroeste do Brasil, o ajardinamento, asfaltamento, a instalação de energia elétrica, de iluminação pública, a instalação de algumas indústrias, o aumento do número de casas comerciais e de agências bancárias no espaço urbano, bem como o melhoramento de vias de transporte terrestre para outras localidades, como, por exemplo, para a região do interior do Estado de São Paulo.

Assim começamos a perceber, como escreveu adequadamente o geógrafo Antônio Firmino de Oliveira Neto, que com a inserção da cidade de Campo Grande no mercado capitalista da região sudeste do país, a lógica de produção e consumo de mercadorias na cidade começará a assimilar as características de um mercado citadino e a tomar a forma de uma cidade (OLIVEIRA, 2005, p. 169), concordando assim o autor com as ideias que a cidade se torna efetivamente uma "cidade" na medida em que a população local satisfaz uma parte economicamente essencial de sua demanda diária (WEBER, 1973, p. 75).

Além das questões econômicas que costumam iniciar o processo de modernização da cidade de Campo Grande, pensamos aqui também nas relações que advém desse crescimento trazendo diversas influências para a vida social dos seus habitantes. A experiência de uma "urbanidade" se manifesta em graus variáveis dentro da própria cidade, sendo marcada por 
indivíduos socialmente heterogêneos com diversos recortes (como classe, raça, natividade). Como poderemos notar na descrição de Celso Costa, professor que afirmou, ainda na década de 1930, que Campo Grande

[...] era uma cidade praticamente independente ${ }^{11}$ Forte no comércio, que alicerçava sua economia, ostentava ares de metrópole, belos clubes e já com dois magníficos teatros, dentre eles o Trianon. A sociedade da época, vestindo-se elegantemente com tecidos importados, desfilava ali sua pompa, em nível de grandes centros, esticando depois para os bailes do Rádio Clube ou pelos elegantes restaurantes da cidade, como a Gruta. Baiana, o bar Bom Jardim, a Confeitaria Delícia e outros tantos locais considerados chiques naqueles tempos. É nessa década que surgem os grandes hotéis e novas casas de espetáculo como o Alhambra e o Santa Helena. Multiplicam-se os palacetes e os chamados "bangalôs" dos ricos e prósperos comerciantes e fazendeiros e a cidade vai ganhando nova fisionomia pelas mãos de engenheiros famosos, a maioria vindos de São Paulo [...]. (COSTA, 1999, p. 76-77, grifo meu)

Esse processo se intensificaria nas décadas posteriores com uma onda de imigração que alteraria a economia da cidade de Campo Grande, assim como inevitavelmente, o espaço urbano do centro de seu entorno. Migração essa estimulada tanto por incentivos governamentai ${ }^{12}$ quanto por incentivos privado ${ }^{13}$. No início de 1950 e nas duas décadas posteriores, teremos uma grande transformação da malha urbana por meio da ocupação do grande número de imigrantes vindos de outros estados da federação, assim como do interior do estado.

Em Campo Grande, como nos demonstra Nataniél dal Moro

[...]torna-se pertinente considerar o aumento de pessoas na zona urbana também como uma questão estrutural, porém delimitado por outra dinâmica. Dados de pesquisas de campo explicitam que esse significativo aumento populacional no espaço urbano da municipalidade de Campo Grande das décadas de 1960 e de 1970 foi consequência da perda do emprego/trabalho no campo, em especial nas lavouras e nas fazendas, por parte dos trabalhadores, muitos dos quais eram propriamente menos trabalhadores e mais posseiros. De toda forma, ficaram sem lugar no campo e rumavam para a cidade. (MORO, 2007, grifo meu)

Com isso, podemos entender melhor a realidade e os motivos da tabela abaixo:

Tabela 1. População rural e urbana de Campo Grande: 1940-198014

\begin{tabular}{|c|c|c|c|c|c|}
\hline População & $\begin{array}{c}\text { Década } \\
\text { de } 1940\end{array}$ & $\begin{array}{c}\text { Década } \\
\text { de } 1950\end{array}$ & $\begin{array}{c}\text { Década } \\
\text { de } 1960\end{array}$ & $\begin{array}{c}\text { Década de } \\
1970\end{array}$ & Década de 1980 \\
\hline Rural & 25.150 & 23.779 & 9.315 & 9.123 & 8.124 \\
\hline Urbana & 24.479 & 33.254 & 64.934 & 131.110 & 283.653 \\
\hline Total & 49.629 & 57.033 & 74.249 & 140.233 & 291.777 \\
\hline
\end{tabular}

Parte desse crescimento se deu conforme a cidade de Campo Grande expandia e se industrializava. Durante esse tempo ela viria a ser conhecida como uma cidade industrial ${ }^{15}$ e, mais amplamente, como a "Capital Econômica de Mato Grosso"16. Essa situação consolida Campo Grande como uma localidade de grande importância no comércio regional, um local onde a instalação de indústrias beneficiava grande parte da produção agropecuária do estado.

11 No trecho de Celso Costa, observarmos outra aproximação com a classificação de cidade weberiana, (WEBER,1973, p.82), ou seja, a autonomia necessária para se formar uma cidade.

12 Podemos citar como exemplo a "Marcha para o Oeste" proposta pelo governo de Vargas na década de 1940, ver mais sobre em (OLIVEIRA, 1999)

13 CAMPOS, Fausto Vieira de. Retrato de Mato Grosso. São Paulo: [s.n.], 1955.

14 FIBGE; SDDI/MS. Evolução da população, por situação de domicílio, segundo os Censos de 1940, 1950,1960, 1970, 1980 e 1991; contagem da população 1996 e Censo 2000. Op. cit., p. 5.

15 O parque industrial do Estado de Mato Grosso, na década de 1950, concentrava-se em sete Municípios: $1^{\circ}$ ) Campo Grande, $2^{\circ}$ ) Corumbá, $3^{\circ}$ ) Aquidauana, $4^{\circ}$ ) Ponta Porã, $5^{\circ}$ ) Vargem Grande e $6^{\circ}$ ) Cuiabá. As atividades industriais calcavam-se na produção de alimentos, de bebidas, de vestuários, além da extração de produtos minerais e de vegetais. Porém, o principal produto que movimentava a economia do Estado ainda era, nesse período, a pecuária. (FIBGE. Op. cit., 1958, p. 122-164.)

16 MORO, Nataniél Dal. "Capital Econômica de Mato Grosso" (Década de 1950). In: Anais do $3^{\circ}$ Encontro de Iniciação Científica e $3^{\circ}$ Fórum de Pesquisa. Umuarama: UNIPAR, p. 31-32, 2004. 
Contudo, é importante ressaltar que mesmo com a crescente expansão da urbanização na cidade de Campo Grande, devemos observar que essa modernização não chegará em todos os habitantes da mesma forma. A infraestrutura surgiria apenas em determinados pontos da cidade. Para Moro, em

[...] particular no interior do espaço composto pelas Avenidas Mato Grosso e Ernesto Geisel e pelas ruas Rui Barbosa e Avenida Fernando Corrêa da Costa. Nesse local havia uma cidade estruturada com modernizações técnicas, algo que além desse espaço era quase que inexistente. (MORO, 2007, p. 110)

Essa relação de poder entre os indivíduos em uma cidade tende a gerar processos de segregação que, como Park (1967, p. 61) demonstra, “[...] fazem da cidade um mosaico de pequenos mundos que se tocam, mas não se interpenetram [...] tende a complicar as relações sociais e a produzir tipos individuais novos e divergentes". Nesse sentido, a cidade aqui, principalmente pós os processos de urbanização, é entendida como um cenário complexo em que diversas relações entre os mais diferentes grupos se dão. A violência urbana, presente neste artigo, pode ser pensada como um dos poucos momentos em que os mundos se encontrariam nesse diverso cenário.

Compreender as modernizações ocorridas nos anos anteriores e nas décadas de 1960 e de 1970, e isso por meio de fontes quase que exclusivamente políticas e econômicas, se torna relevante para que possamos entender como, na cidade de Campo Grande, as questões de urbanidade se constituíram e formaram conflitos e relações de poder entre diversos grupos. Além disso, podemos problematizar como as próprias fontes utilizadas nesse artigo, na medida em que constituem essa ideia de urbanidade e modernidade, foram pautadas apenas por determinados "atores" políticos e econômicos na formação da cidade de Campo Grande como uma "metrópole", sem considerar a contribuição dos "indivíduos comuns" como parte desse processo.

Esses sujeitos, a seu turno, também são agentes ativos na construção da cidade, uma vez que eles dão sustentação a essa grande estrutura, outrora de campo, agora de cidade, seja com mão-de-obra, consumo, enfim, movimentação. No entanto, eles acabam não desfrutando, concreta e diretamente, dos efeitos dessa transformação, pois não residem no "centro" da cidade - o berço mais visível da modernidade local - nem tem condições de consumir os códigos dessa modernidade. Logo, há uma outra Campo Grande, a das periferias distantes do centro, das vulnerabilidades socioeconômicas, das carências infraestruturais, quem sabe até da violência. Dessa forma, na seção seguinte, procuramos pensar alguns aspectos de Campo Grande de hoje em relação ao espaço da cidade e sua utilização cotidiana.

\section{PROBLEMAS DE METRÓPOLES: URBANIZAÇÃO E VIOLÊNCIA}

A história contada até então, acaba por nos dar a impressão de uma cidade que existe quase que independente das pessoas que ali habitam, uma cidade que parece apenas se mover por meio da história e pelas forças econômicas, políticas e históricas. Nessa parte, sem negligenciar as questões históricas já mencionadas na parte anterior, atentaremos mais para a percepção dos sujeitos que habitaram e habitam essa capital.

Apenas buscando contextualizar esse momento, como Silvio Soares Macedo nos diz, a partir da década de 1980, a cidade de Campo Grande irá se consolidar como capital do estado do Mato Grosso do Sul, sendo caracterizada por um avanço dos diversos processos que já vimos anteriormente, de maneira potencializada, com um grande fluxo migratório, de expansão econômica e um intenso processo de urbanização (MACEDO, 2008, p. 106). 
Esse processo de consolidação de Campo Grande como uma cidade gerará, do ponto de vista do estudo urbano, consequência negativas, pois esse processo altera os valores do público e do privado, com o surgimento da cidade e a consolidação do modo de produção capitalista, Richard Sennet nos coloca que o esvaziamento da vida pública e a valorização exacerbada da vida pessoal prevalece em certos grupos da sociedade contemporânea, formando uma nova cultura urbana (SENNET, 1999).

Os novos fluxos de pessoas trazem consigo um significativo aumento no número de estranhos aos moradores "tradicionais". As regras de sociabilidade - que eram construídas entre indivíduos que de alguma maneira, mantinham alguma relação - começam a mudar. Corroborando com Sennet, temos a ideia de que essa nova forma de sociabilidade com uma alta impessoalidade, promovendo uma subjetividade altamente pessoal junto com um aumento das relações calculistas do devir da produção capitalista seriam as essências da atitude blasé ${ }^{17}$ (SIMMEL,1973, p.15-16) demonstradas por Simmel.

Trazendo essa realidade para cidade de Campo Grande observaremos com as falas dos sujeitos que habitam a cidade, numa reportagem do jornal Projétil (aqui deixando claro que o autor do artigo leva em consideração os discursos e interesses que um jornal pode ter nesse campo) dos alunos de jornalismo da Universidade Federal do Mato Grosso do Sul (UFMS) sobre a realidade diária do centro de Campo Grande

[...] O movimento se afunila e se concentra ao redor da praça Ary Coelho: rua 14 de Julho, 15 de novembro, 13 de maio e avenida Afonso Pena. Parte mais conhecida como, de fato, centro. [...]. Às 10h o movimente dos carros torna-se constante, quebrado apenas por semáforos. Assim ele se mantém até a hora do almoço, mudando por volta das 11 h30. Depois de muita relutância, o centro mostra sua vida. O tráfego torna-se frenético e falta espaço nas calçadas. [...]. Os ônibus estão lotados e tanto a chegada quanto a partida de pessoas são como o próprio movimento do centro: constante, rápido e, de forma geral desorganizado. [...]. Correria essa que expõe seu pico ao fim da tarde. $17 \mathrm{~h}$ o centro personifica a própria pressa do trabalhador pela volta ao lar. Agora quase ninguém chega ao local, apenas deixam. (SANDOVAL et al, 2017, p. 3-4, grifo meu).

Na reportagem acima, temos traços característicos das metrópoles, tais como: ideias de "movimento constante, rapidez, velocidade, desorganização, pressa", que acabariam por dar "vida" à cidade e seu centro causando em seus habitantes uma intensificação dos estímulos nervosos, como nos lembra Simmel (1973, p.12). Outras percepções que podemos trazer da reportagem é quanto à questão da cidade sendo vivida em outros horários. A reportagem observou o cotidiano do centro por um dia inteiro, das 7 horas da manhã até às 5 horas da manhã do dia seguinte. Durante a reportagem, diversos sujeitos que vivem cotidianamente suscitam diversas questões que se tornam polos para estudos e entre elas temos as questões de violência urbana e o acesso à cidade.

A problemática de acesso à cidade de Campo Grande por grupos considerados estigmatizados pode ser observada no trabalho de Vladimir Kureda e Guilherme Passamani (2017). Os autores mostram como a partir do processo de fechamento da antiga rodoviária ${ }^{18}$ o espaço ocupado por ela acabou por ser resignificado por diferentes grupos: comerciantes de lanches, vendedores ambulantes e clientes, assim como os sujeitos que serão estigmatizados e considerados como "problema social" pelo estado: moradores de rua, usuários de drogas e prostitutas.

Esse espaço será, muitas vezes, classificado como "degradado" por alguns setores citadino, bem como visto como um local de encontro por grupos considerados subalternos que utilizam daquele espaço, como uma forma de "acessar à cidade", inclusive funcionando como moradia. Além disso, o antigo terminal rodoviário pode ser lido como um espaço de socia-

17 A atitude blasé consiste na consequência de que os indivíduos vivendo em sociedade acabam por adquirir onde o significado e os valores são destituídos de uma certa ingenuidade, sendo hiperacionalizado onde os objetos perdem seu valor simbólico, e apenas se resta o valor econômico determinado pelo dinheiro que se vale, sendo ele o maior nivelador das relações.

18 A antiga rodoviária de Campo Grande foi inaugurada no ano de 1976, momento em que Nataniél Dal Moro (2004) demonstrou o rápido aumento da população urbana. Essa situação permaneceu até o ano de 2000, quando teve início um processo de paulatino esvaziamento em vista da construção de um novo terminal rodoviário e novos shoppings centers em outras regiões da cidade, culminando com seu fechamento em 2010. 
lização e encontro, mostrando assim que o mesmo espaço, já urbanizado, que formou a cidade pode possuir diversas formas de ser experimentado, dependo dos contextos particulares dos grupos que ali interagem.

Já na questão da violência e o medo nas cidades contemporâneas brasileiras têm gerado um fecundo debate nos estudos da antropologia urbana, temos os importantes trabalhos de Feltran (2011) sobre a violência nas periferias de São Paulo, também o trabalho de Paiva (2014) tratando sobre a violência em um território estigmatizado. Aqui focaremos no trabalho de Caldeira (2003) que nos mostra como diferentes grupos sociais, especialmente das classes mais altas, têm usado o medo da violência para justificar tantas novas tecnologias de exclusão social quanto sua retirada de bairros considerados tradicionais da cidade (CALDEIRA, 2003, p.9).

Isso se encontra nos discursos dos moradores da cidade. Joana Abadia, de 78 anos, e Mirtes Macedo, 57, nos contam que "ambas acham perigoso o centro durante a noite. "Tenho medo porque, nossa tá tendo muitas batida, às vezes toma, assalta a gente, né? Principalmente as pessoas idosas, assaltam mesmo", assim como Juscelino do Carmo, 65, diz "Ninguém segura o ladrão. Você pode por uma cerca lá, de dez metros, cerca elétrica, ele corta, entra e te rouba. Pra ele não tem momento ruim" (SANDOVAL et al, 2017, p.4). Essas conversas do dia-a-dia são consideradas frequentes pelas regiões do centro da cidade e são o que Caldeira (2003) chama de falas do crime, que buscam promover uma reorganização simbólica de um universo que foi perturbado pelo crescimento do crime.

Observa-se também a questão do acesso à cidade, especialmente do centro, como nos mostra a reportagem a partir do horário noturno. Um dos maiores exemplos do vazio do centro estaria no fechamento da praça Ary Coelho, onde foram colocadas grades em seu entorno. A praça localizada no coração da cidade fecha diariamente às $22 \mathrm{~h}$. Talvez nada seja mais simbólico que isso (SANDOVAL et al, 2017).

Costumam surgir, neste horário, diversos sujeitos os quais a cidade provavelmente, por meio de suas instituições, não aceitaria que estivessem durante outros horários. Entre eles temos as prostitutas, traficantes, moradores de rua e travestis. Eles costumam se posicionar nas ruas 15 de novembro, 07 de setembro e na avenida Calógeras onde se concentram esses pontos mais escuros que são locais discretos, afinal, tais serviços clamam por isso. Poderíamos pensar nas regiões morais ${ }^{19}$ (PARK, 1967, p. 65), regiões onde prevaleça um código moral divergente.

Nesse horário, no centro, a vigilância da cidade se constitui por um olhar mais atento aos cidadãos que ainda passam por lá. De acordo com Ataíde, gari dessa região, 52, a percepção de quem transita nas ruas centrais costuma estar sempre com medo e em alerta "aqui no centro já vi gente brigando, polícia dando batida e revistando as pessoas. Aqui até às 10 da noite você é cidadão, depois desse horário é meliante" (SANDOVAL et al, 2017, grifo meu). Esses horários, junto com as cercas na praça Ary Coelho, acabam por estabelecer diferenças impondo divisões e distâncias, constroem separações, multiplicam regras de evitação e exclusão, e, ainda como grifado na fala do gari, acabam por restringir os movimentos (CALDEIRA, 2003).

\section{CONSIDERAÇÕES FINAIS}

Ao longo desse artigo, observamos três momentos que fundamentaram a formação e a consolidação da cidade de Campo Grande como o maior polo urbano do estado de Mato Grosso do Sul. Iniciamos o artigo pensando sobre as questões do divisionismo e identidade sul-mato-grossense como o começo de um movimento político que se consolidaria no séc. XX, por

\footnotetext{
19 As regiões morais são entendidas por Park como um local onde indivíduos que buscam as mesmas formas de prazeres se encontram em vias de se realizar a atividade prazerosa de modo a não ser julgado pelos indivíduos, dessa forma se criando uma região moral que possui uma moralidade divergente da sociedade como um todo.
} 
meio da formação do estado e do surgimento da capital. Em um segundo momento, destacamos a cidade de Campo Grande em si enquanto está passava por um processo de modernização e alargamento do "campo" que viria a se tornar realmente "grande”. Já no momento final, buscamos nos aproximar da realidade de Campo Grande atual já como uma das grandes cidades do centro-oeste e os problemas que advém dessa urbanização, particularmente pensando a questão da violência.

Esse artigo pretende ser um, entre outros, elementos disparadores para instigar em Mato Grosso do Sul uma problematização que começa a ganhar fôlego em outras regiões: o estudo das cidades que não são caracterizadas grandes metrópoles, as capitais de porte médio e que estão em outras regiões do país, que não o sudeste. Assim, pensar Campo Grande, é, por alguns momentos, sair das clássicas perspectivas históricas e arquitetônicas, e ir a uma nova perspectiva, trazida aqui pela antropologia urbana. Aqui se observou como existe uma particularidade no que diz respeito à formação de Campo Grande enquanto cidade e depois como capital de estado. Sobressai, ainda, no antigo Arraial de Santo Antônio de Campo Grande de Vacaria, um urbano forjado pelo rural, são os olhos e os braços do campo que criaram a "cidade grande" e as suas "mãos" ainda passeia pelas suas ruas e avenidas. Portanto, a cidade formada pelo movimento político por autonomia de grandes latifundiários da região, a cidade dos filhos dos fazendeiros que haviam ido para os grandes centros de formação do país, continua a carregar uma urbanidade esculpida pelo agronegócio. Temos, então, um urbano pra lá de rural. 


\section{REFERÊNCIAS}

AMARILHA, Carlos Magno Mieres. Os intelectuais e o poder: história, divisionismo e identidade em mato grosso do sul. 2006. 237f. Dissertação (Mestrado) - Curso de História da faculdade de ciências humanas, Universidade Federal da Grande Dourados, Dourados, 2006.

BASSO, Jussara Maria. Investigação de fatores que afetam o desempenho e apropriação de espaços abertos públicos: o caso de Campo Grande - MS. 2001. 227 f. Dissertação (Mestrado em Planejamento Urbano e Regional) - Faculdade de Arquitetura - Universidade Federal do Rio Grande do Sul, Porto Alegre, 2001.

BECKER, Howard. Conferência; A Escola de Chicago. In Mana; Estudos de Antropologia Social, Rio de Janeiro. PPGAS -MN_UFRJ. 1996.pp 177-188

BITTAR, Marisa. Mato Grosso do Sul: do estado sonhado ao estado construído (1892- 1997). 2v. Tese (Doutorado em História Social) - FFLCH/USP, São Paulo, 1997.

CALDEIRA, Teresa Pires do Rio. Cidade de muros: Crime, Segregação e cidadania em São Paulo. Tradução de Frank de Oliveira e Henrique Monteiro. São Paulo: Ed.34/Edusp. 2000.

COSTA, Celso. Evolução urbana. In: CUNHA, Francisco Antônio Maia da (Coord.). Campo Grande: 100 anos de construção. Campo Grande: Matriz, 1999.

FELTRAN, Gabriel de Santis. Fronteiras de tensão: política e violência nas periferias de São Paulo. São Paulo: Editora Unesp, 2011. 376 pp.

FIBGE; SDDI/MS. Evolução da população, por situação de domicílio, segundo os Censos de 1940, 1950,1960, 1970, 1980 e 1991; contagem da população 1996 e Censo 2000. Op. cit., p. 5.

. Enciclopédia dos Municípios Brasileiros. Rio de Janeiro: IBGE, 1958, v. 35. (Mato Grosso).

KUREDA, Vladimir e PASSAMANI, Guilherme. Espacialidade, comércio e degradação. Um olhar etnográfico sobre a antiga rodoviária de Campo Grande-MS. Ponto Urbe [Online], 21 | 2017. Disponível em http://journals.openedition.org/ pontourbe/3524.

LOBATO, Monteiro. De São Paulo a Cuiabá. In: . Mundo da lua e miscelânea. São Paulo: Brasiliense, 1940, v. 10, p. 245 .

MORO, Nataniél Dal. Capital Econômica de Mato Grosso (Década de 1950). In: Anais do $3^{\circ}$ Encontro de Iniciação Científica e $3^{\circ}$ Fórum de Pesquisa. Umuarama: UNIPAR, p. 31-32, 2004.

MORO, Nataniél Dal. Modernização Urbano-Citadina e Representações sobre os trabalhadores na cidade de campo grande (Décadas de 1960-70).2007.357 f. Dissertação (Mestrado em História Social) - Programa de Estudos Pós-Graduados em História Social - Pontifícia Universidade Católica de São Paulo, São Paulo, 2007.

MSPONTOCOM. Agronegócio domina exportações em Mato Grosso do Sul em 2016. Disponível em: < http://mspontocom. com.br/site/agronegocio-domina-exportacoes-em-mato-grosso-do-sul-em-2016/>. Acesso em: 05 ago. 2017.

OLIVEIRA NETO, Antônio Firmino de. A rua e a cidade: Campo Grande e a 14 de julho. Campo Grande: UFMS, 2005.

OLIVEIRA, Benícia Couto de. A política de colonização do Estado Novo em Mato Grosso (1937-1945). 1999. 255 f. Dissertação (Mestrado em História) - Faculdade de Ciências e Letras - Universidade Estadual Paulista Júlio de Mesquita Filho (UNESP/Campus de Assis), Assis, 1999.

OLIVEN, Ruben George. Por uma antropologia em Cidades Brasileiras. In: VELHO, O. G. (Org.). O Desafio da Cidade. Rio 
de Janeiro: Editora Campus LTDA, 1980.

PARK, Robert Ezra. A Cidade: Sugestões para a investigação do comportamento Humano no Meio Urbano. In: VELHO, O. G. (Org.). O fenômeno urbano. Rio de Janeiro: Zahar, 1967.

PAIVA, Luiz Fábio S. Contingências da violência em um território estigmatizado. Campinas: Pontes, 2014.

QUEIROZ, Paulo Roberto Cimó. Divisionismo e "identidade” mato-grossense e sul-mato-grossense: Um breve ensaio. CPDO-UFMS, maio de 2005. 25 p.

SANDOVAL, Fernanda; MARQUES, Marcelle; MESTRE; Rafael; OLIVEIRA, Talita. Cidadania tem limites. Projétil, Campo Grande, p.3-8, № 87 - Ano 27 - abr,mai,junh,2017.

SENNETT, Richard. A Corrosão do caráter: consequências pessoais do trabalho no novo capitalismo. Trad. Marcos Santarrita. Rio de Janeiro: Record, 1999.

SIMMEL, Louis. A metrópole e a vida mental. In: VELHO, O. G. (Org.). O fenômeno urbano. Rio de Janeiro: Zahar, 1973.

WEBER, Max. Conceito e categorias de cidade. In: VELHO, Gilberto (org.). O fenômeno urbano. Rio de Janeiro: Zahar, 1973, pp 73-96.

WEINGÄRTNER, Alisolete Antonia dos Santos. Mato Grosso do Sul: Histórico. Disponível em: < http://www.campogrande. ms.gov.br/arca/artigos/apresentacao-2/>. Acesso em: 12 agosto 2017.

WEINGARTNER, Gutemberg. A construção de um sistema: Os espaços livres públicos de recreação e de conservação em Campo Grande, MS. 2008. 192 f. Tese (Doutorado em Arquitetura e Urbanismo) - Faculdade Arquitetura e Urbanismo - Universidade de São Paulo, São Paulo, 2008.

WIRTH, Louis. O urbanismo como modo de vida In: VELHO, O. G. (Org.). O fenômeno urbano. Rio de Janeiro: Zahar, 1967.

Recebido em: 12/03/2018

Aprovado em: 27/05/2018

Publicado em: 30/11/2018 